\title{
Strategic Management of a Clinical Case of Recurrent Caseaous Lymphadenitis in a Goat Farm
}

\section{Faez Firdaus Abdullah Jesse ${ }^{*}$, Asinamai Athliamai Bitrus ${ }^{2}$, Yusuf Abba $^{2}$, Eric Lim Teik Chung $^{1}$, Muhammad Abubakar SadiQ ${ }^{1}$, Idris Umar Hambali ${ }^{1}$, Heshini Perera ${ }^{1}$, Abd Wahid Haron $^{1}$, Mohd Azmi Mohd Lila ${ }^{2}$, Abdul Aziz Saharee ${ }^{1}$, Mohd Jefri Norsidin ${ }^{1}$, Azrol HARITH $^{1}$}

${ }^{1}$ Department of Veterinary Clinical Studies, Faculty of Veterinary Medicine, Universiti Putra Malaysia, 43400 Serdang, Selangor, Malaysia; ${ }^{2}$ Department of Veterinary Pathology and Microbiology, Faculty of Veterinary Medicine, Universiti Putra Malaysia, 43400 Serdang, Selangor, Malaysia.

\begin{abstract}
This clinical case describes the strategic management of a recurrent caseous lymphadenitis (CLA) in a goat farm. A 3 year old Saanen cross doe was presented with a history of a firm round swelling on the ventral side of the mandible. The goat farm had previous history of CLA three years ago. Blood and serum analysis showed that the doe had leukocytosis, neutrophilia with a left shift and monocytosis. Bacterial culture of the caseaous exudate revealed positive growth for Corynebacterium paratuberculosis. Further clinical examination in the farm revealed that two other goats were infected. To prevent further reinfection, the infected animals were culled. The findings of this clinical case necessitate the need for the adoption of effective biosecurity measures and thorough screening of animals before introducing them into flocks.
\end{abstract}

Keywords | Caseaous lymphadenitis, Corynebacterium paratuberculosis, Doe, Management

Editor | Muhammad Abubakar, National Veterinary Laboratories, Islamabad, Pakistan.

Received | June 04, 2016; Accepted | June 12, 2016; Published | July 10, 2016

*Correspondence | Faez Firdaus Abdullah Jesse, Department of Veterinary Clinical Studies, Faculty of Veterinary Medicine, Universiti Putra Malaysia, 43400

Serdang, Selangor, Malaysia; Email: jesseariasamy@gmail.com

Citation | Jesse FFA, Bitrus AA, Abba Y, Chung ELT, Sadiq MA, Hambali IU, Perera H, Haron AW, Lila MAM, Saharee AA, Norsidin MJ, Harith A (2016).

Strategic management of a clinical case of recurrent caseaous lyphadenitis in a goat farm. Res. J. Vet. Pract. 4(3): 42.46

DOI | http://dx.doi.org/10.14737/journal.rjvp/2016/4.3.42.46

ISSN | 2308-2798

Copyright $(\odot 2016$ Jesse et al. This is an open access article distributed under the Creative Commons Attribution License, which permits unrestricted use, distribution, and reproduction in any medium, provided the original work is properly cited.

G lobally, Caseaous lymphadenitis is considered as one of the most economically significant chronic zoonotic disease of small ruminants causing significant devastation especially in sheep and goat (Abdullah et al., 2013). The disease is characterized by abscess formation in the superficial and peripheral lymph nodes as well as in the internal organs (Cetinkaya et al., 2002). The disease is caused by Corynebacterium pseudotuberculosis which even though was first isolated in 1978 from the sheep's lung, is now considered as a clinical entity in goats (Dercksen et al., 2000). The disease is distributed worldwide and has been reported in Africa, Middle East, Europe and Australia (Osman et al., 2012).

The primary route of transmission is through the contam- ination of superficial wound following procedures such as docking, castration, ear tagging, shearing, and infighting between flocks (Williamson, 2001). Infection can also occur through ingestion of milk from CLA infected animals. Other means of infections includes environmental hazards such as barbed wire, jutting nails, splintered wood which increases the probability of the animals getting infected (Cetinkaya et al., 2002; Williamson, 2001).

Significant economic losses attributed to CLA occur due to poor wool growth, wasting, reduction in the quantity and quality of milk, premature culling, carcass condemnation, reproductive disorders and in some cases death (Paton et al., 1994). The disease causes a significant economic loss to small ruminant farmers in Australia, United States and 
Canada, with an estimated annual loss of about 17 million dollars in Australia alone (Cetinkaya et al., 2002). In addition, since CLA is not a notifiable disease in many countries, the actual prevalence of the disease is usually played down giving room for the disease to occur without it being noticed (Windsor, 2011). Furthermore, since most farmers and animal owners are also not aware of the economic implication of the disease, they do not usually seek the attention of a veterinarian in cases of occurrence of superficial abscess which is known to facilitate the spread of the disease (Osman et al., 2012). However, a prevalence of up to about $8 \%$ to $90 \%$ has been reported in other countries (Cetinkaya et al., 2002). The disease has also been reported in Malaysia (Abdullah et al., 2013; Komala et al., 2008). In addition, the occurrence of the disease due to importation of animal has been reported in countries previously considered free of CLA (Møller et al., 2000). In humans, CLA is rarely reported and if it does occur, the disease is as a result of exposure to infected animals or ingestion of contaminated milk and raw meat from infected animal (Peel et al., 1997).

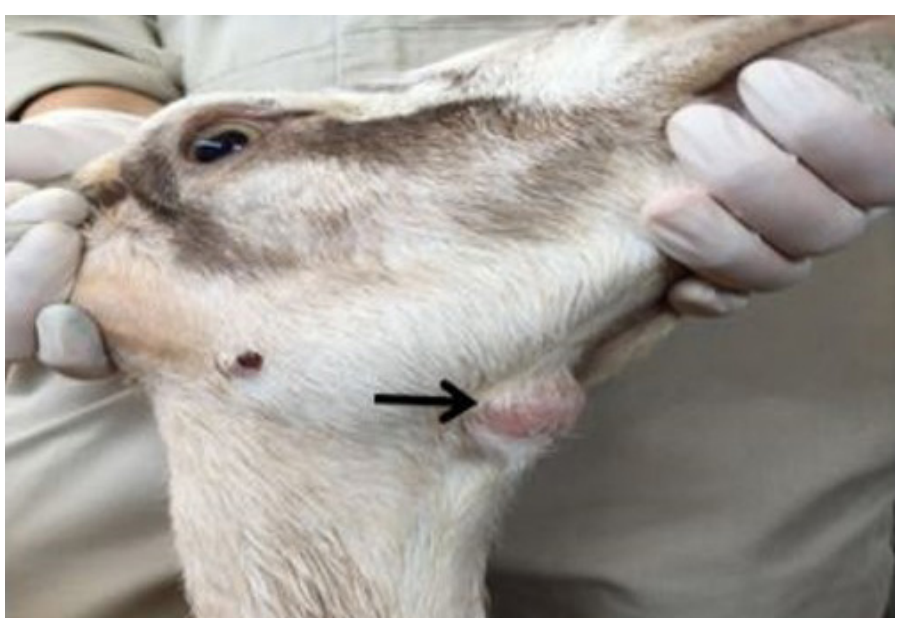

Figure 1: Round firm swelling on the ventral side of the mandible

The diagnosis of CLA is primarily based on isolation of the causative organism from abscess and observation of characteristic clinical symptoms and serological test such as ELISA, complement fixation test, hemolysis inhibition test and immunodiffusion test (Abdullah et al., 2011; Cetinkaya et al., 2002). The control and prevention of the disease is difficult due to the rapid spread of the organism once introduced. However, a variety of vaccines has been developed for the eradication of CLA (Roslindawani et al., 2016) and has proven to give a promising result. This case report describes the management of recurrent case of caseaous lymphadenitis in a goat farm in Malaysia.

\section{CASE HISTORY}

\section{Case Presentation}

A 3 year old female Saanen cross doe was presented to the
University Veterinary Hospital, Universiti Putra Malaysia with the complaint of swelling on the lower right mandible, which was first noticed three weeks prior to presentation. Clinical history revealed that the farm previously had CLA and was depopulated in 2008 in order to reduce the risk of spread of the disease. However, it was observed that the disease reoccurred after three years.

\section{Physical Examination}

Physical examination revealed a round firm, non-movable and non-painful mass on the ventral side of the mandible and an enlarged sub mandibular lymph node which was $1.5 \times 1.5$ centimeter in size (Figure 1). Vital parameters revealed that the doe had rectal temperature of $39.2{ }^{\circ} \mathrm{C}$, respiratory rate of 36 cycles per minute and pulse rate 72 beats per minute, respectively.

\section{Diagnostic Work Plan}

The swollen area was aseptically prepared and fine needle aspiration biopsy was attempted; however, there a caseaous exudate oozed out immediately the needle was removed (Figure 2). The exudate was collected in a plain tube for bacterial culture and identification while blood sample was collected for complete blood count and serum biochemistry. The result of the bacterial culture revealed a heavy growth of Corynebacteria pseudotuberculosis, while complete blood count showed leukocytosis and neutrophilia with a regenerative left shift and monocytosis thus, suggestive of an ongoing inflammatory process.

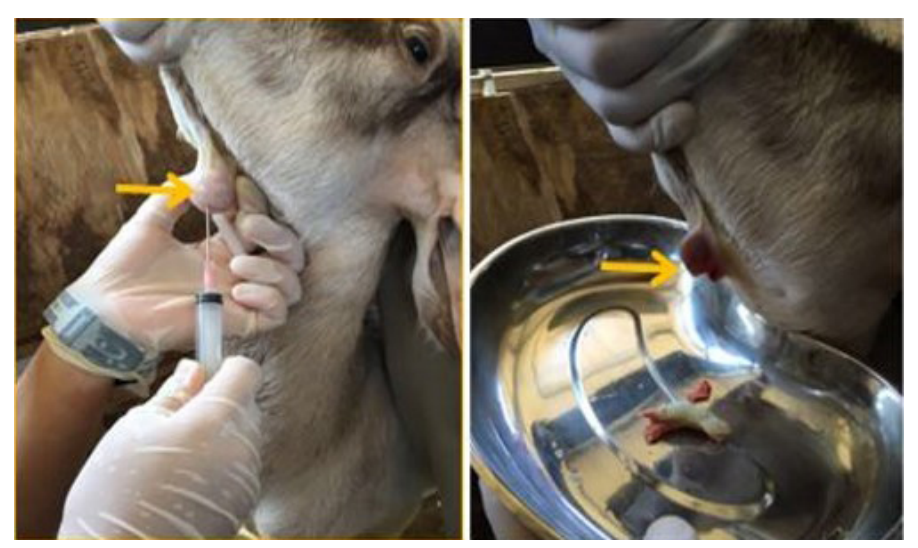

Figure 2: Excised Caseaous exudate and fine needle aspiration biopsy

\section{Treatment Plan}

The doe and other two showing clinical manifestation of CLA were culled in order to limit the spread of the disease to other healthy animals in the farm.

\section{DISCUSSIONS}

Caseaous lymphadenitis (CLA) continues to pose a serious problem to the small animal industries, thus limiting their economic profitability. It has been observed that the 
sustained marketing and movement of small ruminants from one country to the other without the use of adequate biosecurity measures greatly limit the control and prevention of CLA (de Sá Guimarães et al., 2011). Thus, maintaining the prevalence of CLA at its peaks, indicating the need for adopting a sustainable control measures. It is worthy of note, that difficulty abounds in development and application of an effective diagnostic plan. It is therefore important to have effective immunogens which can be use in vaccination (de Sá Guimarães et al., 2011).

Cases of CLA in humans are rare and if reported in most cases it is related to exposure as a result of contact with infected animals. However, cases of CLA in humans due to the ingestion of raw cow and goat meat have been reported (Peel et al., 1997). In addition, about 25 cases of human infection have also been reported thus, indicating the zoonotic potential of CLA. Mills et al. (1997) reported a case of suppurative granulomatous lymphadenitis in a boy who has contact with farm animals. This finding validates the zoonotic implication of CLA and the need to develop an effective biosecurity measures to guard against infections to humans. Furthermore, Peel et al. (1997) in their review also reported that about 22 cases of human CLA is characterized by lymphadenitis, abscesses and other similar symptoms. In all cases, patients were treated with antibiotics and the affected lymph nodes surgically removed.

The clinical management of CLA revolves around early detection of the disease in a herd and culling of infected animals showing clinical manifestation of the disease. Due to the chronic nature of the disease, the tendency of the disease to spreading rapidly in the herd without the farmer knowing until the development of clinical manifestation is high (Osman et al., 2015). One of the major challenges in the management of CLA is attributed to the fact that many farmers and animal owners have little or no knowledge of the disease thus, facilitating the rapid spread of the disease among the herd. For instance, in Malaysia only about $14.8 \%$ of the farmers have knowledge of CLA (Osman et al., 2012). CLA disease causes significant economic loss to small ruminant industry, therefore, it is important to design measures that will aim at reducing the rate of spread of the disease.

For instance, bacteria induced caseation necrosis of the lymph nodes is one of the major manifestation of CLA in small ruminants and the organism have been known to persist within the infected lymph node. The most frequently observed clinical manifestation is abscess formation in the peripheral lymph nodes, subcutaneous tissue and involvement of the visceral organs (Dorella et al., 2006). This is in agreement with the finding of this case report, because clinical history revealed a round firm swelling on the ventral side of the mandible and caseaous exudate upon exci- sion (Figure 2). Furthermore, it has been observed that the abscess can persist for about two to three years containing the viable organism, thus, serving as a potential source of reinfection of the flocks (de Sá Guimarães et al., 2011).

Because CLA is a disease of great economic and zoonotic importance, there is the need to design an effective strategic plan for its control and eradication in areas where the disease is endemic. Such strategies can involve measures such as reducing the number of infected animals to such a level that it doesn't pose a significant threat to animal welfare and public health. Other measures such as test and slaughter method should also be employed. The key to successful eradication of CLA in an endemic area involves the implementation of an active surveillance system supported by a fully equipped laboratory (Osman et al., 2015). Given the nature of the spread of CLA, the treatment of the disease is in effective and expensive. The best strategy adopted so far for the prevention and control of the disease in countries where the prevalence of the disease is high is through vaccination against the causative organism and this have however proven to give a very good result (Dorella et al., 2006; Roslindawani et al., 2016). An effective strategy however should be based on frequent clinical inspection, and serologic testing of all animals in the flock from time to time, including the recently purchased animals, and those that have been returned to the herd while culling those that are serologically positive or those showing clinical disease (de Sá Guimarães et al., 2011). This is because it has been observed that once the animal has been infected, it is difficult to completely eradicate the causative organism. For instance, in an eradication programme, there is need to accurately measure the predictive value of the test used in detecting the presence of CLA before a decision of culling an infected animal is made. This is because, increase or decrease in the prevalence of the disease affects the outcome of the test and thus can led to poor judgement which invariably results in under or over reporting the occurrence of the disease in a herd (Dercksen et al., 2000). In addition, given the important role played by subclinically infected animals in the introduction and spread of CLA into a herd, serological diagnosis has proven to be very useful in the control and eradication of CLA. Serological test such as compliment fixation test (CFT), ELISA, hemolysis inhibition test and immunodiffusion test are usually employed in the diagnosis of CLA. In spite of the limitations of these tests, ELISA has proven to be an exceptionally versatile tool in the control and eradication of CLA (Cetinkaya et al., 2002).

The implementation of biosecurity procedures in all flocks must especially during the introduction of new animals have showed reduction in the rate of infection (Campbell et al., 1982). This is because; the focal point of entry of the disease into the herd is the introduction of new animals 
into the herd. In this case report it was observed that the farm have had a history of CLA even though the farm had been depopulate, the use of infective biosecurity measures might have been the cause of reinfection of the farm.

Other measures aimed at reducing the impact of the disease in order to reduce the associated losses due to the occurrence of the disease is involves effective control of insects and disinfecting the umbilical cord of the neonates and skin abrasions with 10\% iodine (de Sá Guimarães et al., 2011). Measures aimed at reducing environmental risk such as the use of smooth wires to fence pens, proper and frequent disinfection of the ear tagging and shearing instruments should be encouraged (Abdullah et al., 2013). Furthermore, since majority of the farmers are not aware of the implication of the disease, it is important to help educate the animal owners and farm personnel on the economic importance of the disease and be encouraged to report any case of CLA to the veterinarians. In addition, information about the zoonotic potentials of the organism should be made available to farmers and people who live around the farm environment or are involved directly in taking care of the animals. Strict adherence to this control measures will greatly help in reducing the outbreak of CLA.

\section{CONCLUSION}

This clinical case showed the importance of effective implementation of vaccination strategies and other control measures in the control and prevention of CLA in small ruminants and its zoonotic implications in humans.

\section{ACKNOWLEDGEMENT}

The authors wishes to appreciate the management and staff of University Veterinary Hospital, Universiti Putra Malaysia (UPM) for their cooperation.

\section{CONFLICT OF INTEREST}

None to declare.

\section{AUTHORS' CONTRIBUTION}

All authors contributed equally and approved the final manuscript.

\section{REFERENCE}

-Abdullah FFJ, Lau SS, Saharee AA, Shamsudin S (2011). Pathological changes in the organs of mice model inoculated with Corynebacterium pseudotuberculosis organism. Pertanika J. Trop. Agric. Sci. 34(1): 145-149.
-Abdullah FFJ, Osman AY, Adamu L, Azri NA, Wahid A (2013). Caseous Lymphadenitis in a Goat. Vet. J. 52: 513-514.

-Campbell SG, Ashfaq MK, Tashjian JJ, (1982) Caseous lymphadenitis in goats in the USA. In: Proceedings of the Third International Conference on Goat Production and Disease. Tucson, pp. 449-454.

- Cetinkaya B, Karahan M, Atil E, Kalin R, De Baere T, Vaneechoutte M (2002). Identification of Corynebacterium pseudotuberculosis isolates from sheep and goats by PCR. Vet. Microbiol. 88(1): 75-83. http://dx.doi.org/10.1016/S03781135(02)00089-5

-de Sá Guimarães A, Do Carmo FB, Pauletti RB, Seyffert N, Ribeiro D, Lage AP, Gouveia AMG (2011). Caseous lymphadenitis: epidemiology, diagnosis, and control. IIOAB J. 2: 33-43.

-Dercksen DP, Brinkhof JMA, Dekker-Nooren T, van Maanen K, Bode CF, Baird G, Kamp EM (2000). A comparison of four serological tests for the diagnosis of caseous lymphadenitis in sheep and goats. Vet. Microbiol. 75(2): 167-175. http:// dx.doi.org/10.1016/S0378-1135(00)00217-0

-Dorella FA, Pacheco LGC, Oliveira SC, Miyoshi A, Azevedo V (2006). Corynebacterium pseudotuberculosis: microbiology, biochemical properties, pathogenesis and molecular studies of virulence. Vet. Res., 37(2): 201-218. http://dx.doi. org/10.1051/vetres:2005056

-Komala TS, Ramlan M, Yeoh NN, Surayani AR, Sharifah HSM (2008). A survey of caseous lymphadenitis in small ruminant farms from two districts in Perak, Malaysia-Kinta and Hilir Perak. Trop. Biomed. 25(3): 196-201.

-Liu DT, Chan WM, Fan DS, Lam DS (2005). An infected hydrogel buckle with Corynebacterium pseudotuberculosis. Br. J. Ophthalmol. 89: 245-246. http://dx.doi.org/10.1136/ bjo.2004.051698

•Mills AE, Mitchell RD, Lim EK (1997) Corynebacterium pseudotuberculosis is a cause of human necrotizing granulomatous lymphadenitis. Pathol. 29 (2): 231-233.

-Møller K, Agerholm JS, Ahrens P, Jensen NE, Nielsen TK (2000). Abscess disease, caseous lymphadenitis, and pulmonary adenomatosis in imported sheep. J Vet. Med. Series B. 47(1): 55-62. http://dx.doi.org/10.1046/j.14390450.2000.00310.x

- Osman AY, Abdullah FFJB, Saharee AA (2012). SeroPrevalence of Caseous Lymphadenitis Evaluated by Agar Gel Precipitation Test among Small Ruminant Flocks in East Coast Economic Regions in Peninsular Malaysia. J. Anim. Vet. Adv. 11: 3474-3480. http://dx.doi.org/10.3923/ javaa.2012.3474.3480

- Osman AY, Abdullah FFJ, Chung ELT, Abba Y, Sadiq MA, Mohammed K, Lila MAM, Haron AW, Saharee AA (2015). Caseous Lymphadenitis in a Goat: A case report. Int. J. Livest. Res. 5: 128-132. http://dx.doi.org/10.5455/ ijlr.20150221071744

-Paton MW, Rose IR, Hart RA, Sutherland SS, Mercy AR, Ellis TM,DhaliwalJA (1994). New infection with Corynebacterium pseudotuberculosis reduces wool production. Aust. Vet. J. 71: 47-49. http://dx.doi.org/10.1111/j.1751-0813.1994. tb06152.x

-Peel MM, Palmer GG, Stacpoole AM, Kerr TG (1997). Human lymphadenitis due to Corynebacterium pseudotuberculosis: Report of ten cases from Australia and review. Clin. Infect. Dis. 24: 185-191. http://dx.doi.org/10.1093/ clinids/24.2.185

-Roslindawani MN, Syafiqah AS, Jesse FFA, Effendy AW, 
Zamri-Saad M (2016). Recombinant caseous lymphadenitis vaccine with palm oil as adjuvant enhances the humoral and cell-mediated immune responses in rat model. J. Anim. Health Prod. 4: 22-25. http://dx.doi.org/10.14737/journal. jahp/2016/4.1.22.25

-Williamson LH (2001). Caseous lymphadenitis in small ruminants. Vet. Clinic. North Am. Food Anim. Pract. 17(2): 359-371.http://dx.doi.org/10.1016/S0749-0720(15)30033-

5

-Windsor PA (2011). Control of caseous lymphadenitis. Vet. Clinic. North Am. Food Anim. Pract. 27(1): 193-202. http://dx.doi.org/10.1016/j.cvfa.2010.10.019 